\title{
To compare the effectiveness of recombinant gonadotropin versus the combination of recombinant follicle stimulating hormone and highly purified human menopausal gonadotropin versus urinary human menopausal gonadotropin alone for ovarian stimulation in women undergoing in vitro fertilisation or intracytoplasmic sperm injection treatment cycles
}

\author{
Pratibha Vishwakarma*, Kundavi Shankar, Indumathi Joy, Thankam R. Varma
}

Institute of Reproductive Medicine and Women's Health, Madras Medical Mission Hospital, Mogappair, Chennai, Tamilnadu, India

Received: 14 March 2016

Received: 09 May 2016

Accepted: 09 May 2016

\section{*Correspondence:}

Dr. Pratibha Vishwakarma,

E-mail: pratibha_vish@yahoo.co.in

Copyright: () the author(s), publisher and licensee Medip Academy. This is an open-access article distributed under the terms of the Creative Commons Attribution Non-Commercial License, which permits unrestricted non-commercial use, distribution, and reproduction in any medium, provided the original work is properly cited.

\section{ABSTRACT}

Background: The question of the dominance of recombinant FSH(r FSH) for controlled ovarian stimulation (COS) in in-vitro fertilization (IVF) is not yet defined. Cheaper and equally efficient drugs for COS are valuable for the poor infertile couple.

Methods: This retrospective study includes total of 371 fresh, non-donor, IVF cycles with COS excluding PCOS, endometriosis and poor ovarian reserve patients. To minimize the bias, only the first cycle for each patient below 40 years old, in one year period (Jan 2014 to Dec 2014) was analyzed. This selection comprised of respondents in 3 groups i.e. $\mathrm{rFSH} n=132$, HP-HMG $+\mathrm{rFSH}, \mathrm{n}=141$ and $\mathrm{uHMG}, \mathrm{n}=98$. The primary outcome studied as the result of COS are the mean number of retrieved oocytes and mature oocytes, fertilization rate, mean number of good quality embryos, and -cryopreserved embryos. The secondary outcome was the clinical pregnancy rates and the delivery rates.

Results: The current studies do not demonstrate significant differences in duration and dosage of gonadotropins required and clinical outcome of treatment in patients in all 3 groups. We found significant higher E2 levels \&better quality oocytes an embryo in patients treated with uHMG and combination groups \& significantly increased number of cryopreserved embryos in uHMG group. Lower cancellation rates in rFSH group and HMG group. OHSS rates were similar in all 3 groups.

Conclusions: Treatment with uHMG or with combination could achieve the same results and reduce the whole cost of stimulation in comparison with $\mathrm{rFSH}$

Keywords: Maternal death, Mortality Related to Pregnancy, Pregnancy, Mortality

\section{INTRODUCTION}

In the last decade the number of gonadotropins available for ovulation induction and controlled ovarian stimulation (COS) has rapidly expanded. In addition to the introduction of various types of recombinant (r) preparations such as r FSH (a and b), r LH and r CG, better human-derived gonadotropins have also entered the market. Highly purified (HP) hMG is the latest addition to this family of infertility drugs. The purification process of $\mathrm{HP} \mathrm{hMG}$ allows its administration through the subcutaneous route with an incidence of local cutaneous reactions comparable with recombinant products. A recent large multicentre trial comparing $\mathrm{HP}$ hMG with rFSHa in 727 treatment cycles has shown that these two drugs appear to be equally effective when employed in 
assisted reproductive technology programmes. ${ }^{1}$ The question of the dominance of recombinant FSH for COS in IVF, as most new medications over other forms of gonadotropins is available, is not yet defined. Studies give advantage to one preparation over the others. A cheaper and equally efficient drug for COS is necessary for the poor infertile couple, prevalent in a developing country like India.

\section{METHODS}

This retrospective study is done at Institute of Reproductive Medicine and Women's health, Madras Medical Mission, Chennai, India. This study includes total of 371 fresh, non-donor, IVF/ICSI cycles with controlled ovarian stimulation (COS) excluding PCOS, endometriosis and poor ovarian reserve patients as these conditions could affect the oocyte and embryo quality. To minimize the bias, only the first cycle for each patient below 40 years old, in a year period i.e. Jan 2014 to Dec 2014, was analysed. This selection comprised of respondents in 3 groups i.e. $\mathrm{rFSH}, \mathrm{n}=132$, $\mathrm{HP}-\mathrm{HMG}$ + rFSH, $n=141$ and $\mathrm{HHMG}, \mathrm{n}=98$. All patients had antagonist protocol. From day 2 of the period, Gonadotropins (Gonal F, Recagon, Menopure, IVF M) according to the group was started and antagonist (Cetrorelix) was added after 5 days of gonadotropins till the day of hCG trigger. E2 level was measured on the day of trigger. Oocyte retrieval was done under USG guidance and under intravenous sedation. After oocytes screening i.e. GV, MI or M II and oocytes abnormality (giant oocytes, large perivitelline space, fragments in perivitelline space, large or too small first polar body and fragmented polar body, presence of refractile body, large or small vacuole and smooth endoplasmic reticulum (SER) in the cytoplasm, all M II oocytes were injected (ICSI) with good morphology sperms. Developmental status of embryos were checked at fertilization i.e. 2 PN stage and at 4 cell stage. Number of embryos having cleavage arrest or rapid cleavage were noted and embryos had been graded according to morphological criteria i.e. degree of fragmentation and symmetry of blastomeres. According to the developmental status of the embryos they were transferred on day 2, day 3 or blastocyst stage. Fresh embryo transfer using after loading technique was done with endometrial thickness between 8-12 mm with good sub endothelial blood flow. Average 3 embryos were transferred in all 3 groups. In few patients with recurrent implantation failure 4 embryos were transferred. Surplus embryos were cryopreserved and elective cryopreservation of embryos in patients with high estradiol level to prevent ovarian hyperstimulation syndrome. After embryo transfer luteal support was given in form of, vaginal and injectable progesterone preparation. In patients with recurrent implantation failure or with impaired thrombophilia profile Low molecular weight heparin $40 \mathrm{mg}$ subcutaneously and oral aspirin $75 \mathrm{mg}$ was added. Pregnancy test with serum $\beta$ hCG was done 16 days after the embryo transfer. The primary outcome studied as the result of COS are the mean number of retrieved oocytes and mature oocytes, fertilization rate (FR), number of embryos with cleavage arrest, mean number of good quality embryos, and cryopreserved embryos. The secondary outcome was the cancellation rate, clinical pregnancy rates (CPR), implantation rate (IR), on-going pregnancy report (OPR) and the live birth rate (LBR). Implantation rate was determined by number of embryos transferred and number of gestational sacs on transvaginal sonography (TVS). Clinical pregnancy was documented by transvaginal sonography near 6 weeks of gestation with cardiac activity. On-going pregnancy rates were documented with fetus with good cardiac activity at 12 weeks of gestation.

Data was analysed using Chi square test and Student's t test

\section{RESULTS}

Table 1: Clinical parameters in all 3 groups.

\begin{tabular}{|c|c|c|c|c|c|c|}
\hline Parameters & $\begin{array}{l}\text { Recombinant FSH } \\
(\mathrm{n}=132)\end{array}$ & $\begin{array}{l}\text { HMG + recombinant } \\
\text { FSH }(n=141)\end{array}$ & $\begin{array}{l}\text { Urinary HMG } \\
(98)\end{array}$ & $\begin{array}{l}\text { Sig } \\
\text { (P value) }\end{array}$ & $\begin{array}{l}\text { Sig } \\
\text { (P value) }\end{array}$ & $\begin{array}{l}\text { Sig } \\
\text { (P value) }\end{array}$ \\
\hline & Mean & SD & Mean & SD & Mean & SD \\
\hline Age (yrs) & 26 & 4 & 27 & 5 & 26 & 2 \\
\hline BMI (kg/m2) & 24.5 & 2.4 & 25 & 2 & 24.6 & 2.6 \\
\hline Type of infertility & $102 / 30$ & & $109 / 32$ & & $75 / 23$ & \\
\hline $\begin{array}{l}\text { Partner's S/A } \\
(\mathrm{X} \mathrm{106)}\end{array}$ & 20 & 4 & 19.5 & 3.5 & 22 & 3.2 \\
\hline FSH (IU/L) & 7 & 0.4 & 7.1 & 0.6 & 7 & 0.5 \\
\hline LH (IU/L) & 4.5 & 0.5 & 4.6 & 0.4 & 4.5 & 0.8 \\
\hline PRL(ng/ml) & 16.5 & 2.4 & 17 & 1.9 & 16.7 & 2 \\
\hline E2 (pg/ml) & 46 & 2 & 45.6 & 2.4 & 45.3 & 2.5 \\
\hline
\end{tabular}


Table 2: Amount of gonadotropins and oocyte maturity in all 3 groups.

\begin{tabular}{|c|c|c|c|c|c|c|}
\hline Parameters & $\begin{array}{l}\text { Recombinant FSH } \\
(n=132)\end{array}$ & $\begin{array}{l}\text { HMG + recombinant } \\
\text { FSH }(n=141)\end{array}$ & $\begin{array}{l}\text { Urinary } \\
\text { HMG (98) }\end{array}$ & Sig & Sig & Sig \\
\hline & Mean & SD & Mean & SD & Mean & SD \\
\hline $\begin{array}{l}\text { Average no. of days of } \\
\text { gonadotropin } \\
\text { administration }\end{array}$ & 10 & 1 & 9.8 & 2 & 9.7 & 2.1 \\
\hline $\begin{array}{l}\text { Average dose of } \\
\text { gonadotropin }\end{array}$ & 2250 & 100 & 2275 & 125 & 2220 & 200 \\
\hline E2 on trigger & 1700 & 75 & 2127 & 90 & 2250 & 80 \\
\hline No of oocytes retrieved & 8.3 & 2.1 & 7.7 & 3 & 7.8 & 2.4 \\
\hline GV & 1 & 0.11 & 0.85 & 0.985 & 1 & 0.2 \\
\hline M1 & 0.6 & 0.1 & 0.63 & 0.2 & 0.39 & 0.2 \\
\hline M2 & 6.7 & 0.23 & 6.65 & 0.3 & 6.68 & 0.25 \\
\hline
\end{tabular}

Table 3: Comparison of oocyte quality in all 3 groups.

\begin{tabular}{|c|c|c|c|c|c|c|}
\hline Parameters & $\begin{array}{l}\text { Recombinant FSH } \\
(\mathrm{n}=132)\end{array}$ & $\begin{array}{l}\text { HMG + } \\
\text { recombinant FSH } \\
(\mathrm{n}=141)\end{array}$ & $\begin{array}{l}\text { Urinary } \\
\text { HMG (98) }\end{array}$ & Sig & Sig & Sig \\
\hline & Mean & SD & Mean & SD & Mean & SD \\
\hline Central granularity & 0.76 & 0.2 & 0.42 & 0.1 & 0.62 & 0.3 \\
\hline Multiple vacuole & 0.66 & 0.1 & 0.08 & 0.001 & 0.08 & 0.02 \\
\hline Empty zona/thick zona & 0.27 & 0.1 & 0.28 & 0.12 & 0.26 & 0.01 \\
\hline Thick zona/no zona & 0.09 & 0.01 & 0.007 & 0.001 & 0 & 0 \\
\hline Large PV space & 0.53 & 0.01 & 0.03 & 0.02 & 0.07 & 0.02 \\
\hline $\begin{array}{l}\text { Large/fragmented } \\
\text { polar body }\end{array}$ & 0.1 & 0.01 & 0.101 & 0.01 & 0 & 0 \\
\hline Giant oocyte & 0.0075 & 0.001 & 0 & 0 & 0 & 0 \\
\hline SER & 0.16 & 0.01 & 0 & 0 & 0.04 & 0.2 \\
\hline $\begin{array}{l}\text { No of abnormal oocyte } \\
(\%)\end{array}$ & 30.9 & & 11.4 & & 13.1 & \\
\hline Total no. of embryos & 6.7 & 0.2 & 6.68 & 0.196 & 6.66 & 0.3 \\
\hline Grade A & 5.08 & 0.3 & 5.3 & 0.2 & 4.5 & 0.2 \\
\hline Grade B & 1.5 & 0.1 & 0.6 & 0.1 & 1.3 & 0.1 \\
\hline Grade C & 0.09 & 0.01 & 0.02 & 0.01 & 0.04 & 0.1 \\
\hline
\end{tabular}

Table 4: Comparison of clinical outcome in all 3 groups.

\begin{tabular}{|c|c|c|c|c|c|c|}
\hline Parameters & $\begin{array}{l}\text { Recombinant FSH } \\
(\mathrm{n}=132)\end{array}$ & $\begin{array}{l}\text { HMG + recombinant } \\
\text { FSH }(\mathrm{n}=\mathbf{1 4 1})\end{array}$ & $\begin{array}{l}\text { Urinary } \\
\text { HMG (98) }\end{array}$ & Sig & Sig & Sig \\
\hline & Mean & SD & Mean & SD & Mean & SD \\
\hline OHSS (mild/mod/severe) Rate (\%) & $24 / 3 / 1(28.0 \%)$ & & $\begin{array}{l}23 / 5 / 1 \\
(29.0 \%)\end{array}$ & & $\begin{array}{l}24 / 6 / 2 \\
(32 \%)\end{array}$ & \\
\hline Cancellation rate (\%) & 15.9 & 0.1 & 29.4 & 0.4 & 18.3 & 0.2 \\
\hline Fertilization rate $(\%)$ & 79.7 & 3 & 79.4 & 3.1 & 80 & 2.9 \\
\hline $\begin{array}{l}\text { No. of cleavage arrest or rapid cleavage } \\
(\%)\end{array}$ & 16.9 & 2.5 & 16.4 & 2.8 & 16.7 & 2.6 \\
\hline Average no. of embryos transferred & 3.4 & 0.2 & 3.42 & 0.19 & 3.4 & 0.21 \\
\hline D2/D3 transfer/blastocyst & $38 / 68 / 5$ & & $52 / 48 / 0$ & & $37 / 43 / 0$ & \\
\hline No. of embryos cryopreserved & 2.7 & 0.1 & 2.66 & 0.1 & 2.7 & 0.11 \\
\hline Implantation rate & 46.8 & 5.2 & 47.1 & 4.8 & 45.9 & 5.4 \\
\hline CPR $(\%)$ & 36.3 & 2.4 & 35.9 & 2.6 & 35.6 & 2.45 \\
\hline OPR (\%) & 30.3 & 4.2 & 29.9 & 3.8 & 30.5 & 4.1 \\
\hline LBR $(\%)$ & 22 & 2.1 & 22.4 & 2.8 & 21.8 & 2.2 \\
\hline Pregnancy rate per embryo transfer $(\%)$ & 43.2 & 6.4 & 42.8 & 5.4 & 42.4 & 6 \\
\hline Twin & 12 & & 9 & & 6 & \\
\hline Miscarriage rate $(\%)$ & 6 & 1.4 & 6.1 & 1.38 & 5.9 & 1.42 \\
\hline
\end{tabular}


The current study does not demonstrate significant differences in duration and dosage of gonadotropins required. We found significant higher E2 levels in patients treated with uHMG $(2127 \pm 90)$ and combination groups $(2250 \pm 80)$. There was no significant difference in clinical outcome of treatment in patients in all 3 groups i.e. Fertilization rate (FR), Implantation rate (IR),Clinical pregnancy rate (CPR), On-going pregnancy rate (OPR) and Live birth rate (LBR) Significantly increased number of cryopreserved embryos $(2.7 \pm 0.11)$ in $\mathrm{uHMG}$ group were present quality of embryos (Grade A: $5.3 \pm 0.2$ and 4.5 \pm 0.02 , Grade B: $0.6 \pm 0.1$ and $1.3 \pm 0.1$, Grade C: $0.02 \pm 0.01$ and $0.04 \pm 0.1$ ) were significantly better in combination group and in $\mathrm{u}$ HMG group and oocytes abnormalities were less in combination group (11.4\%) and $\mathrm{UHMG}$ group (13.1\%). Lower cancellation rates $(15.9 \% \pm 0.1)$ in $\mathrm{rFSH}$ group and HMG group (18.3 \pm 0.2$)$. OHSS rates were similar in all 3 groups.

Table 5: Comparison of cost of different drugs used.

\begin{tabular}{|lll|}
\hline $\begin{array}{l}\text { Generic name } \\
\text { Menotropin urinary }\end{array}$ & Unit & Cost (Rs.) \\
HMG & 150 & 850 \\
\hline HP menotropin & 150 & 1900 \\
\hline Recombinant FSH & 150 & $\begin{array}{l}3140 \\
(850 X 3.6 \& 1900 X 1.6)\end{array}$ \\
\hline
\end{tabular}

\section{DISCUSSION}

Although follicular growth can be induced by FSH alone, it needs the LH threshold for proper development. ${ }^{2,3}$ Current study do not demonstrate significant differences in duration and dosage of gonadotropins required. Most previous studies comparing FSH-only gonadotropin preparations with menotropins (providing both FSH and LH activity) failed to uncover significant differences in treatment duration or gonadotropin dose requirements. ${ }^{2,4}$ We found significant higher E2 levels in patients treated with $\mathrm{uHMG}$ and in the combination group. The finding of significantly higher E2 levels in patients treated with HP hMG and combination group seems to confirm indirectly that this preparation contains greater amounts of $\mathrm{LH}$ activity. However, the increment in serum E2 could be due to: (i) an increase in the androgen substrate produced by LH activity-stimulated theca cells (which nevertheless could not be detected through peripheral serum measurements of testosterone; (ii) to the direct actions of LH activity on the granulosa cell aromatase system of larger follicles that became responsive to $\mathrm{LH}$ through the acquisition of specific receptors (iii) better stimulation of the aromatase system by the increased immunoreactive FSH concentrations found in the HP hMG group; or through a combination of these factors. ${ }^{5,6} \mathrm{We}$ observed significantly increased number of cryopreserved embryos in uHMG group and hence increased cumulative pregnancy rates, similar to previous studies. ${ }^{6}$ Quality of embryos were significantly better in combination group and oocyte abnormalities were less in combination and in uHMG groups unlike with the previous studies. ${ }^{7}$ Lower cancellation rates (15.9\%) were seen in rFSH group. OHSS rates were similar in all 3 groups but other studies found more in HMG group. When we analysed the specific features of the ICSI procedure, we could not identify any significant difference in clinical outcome of treatment in patients in all 3 groups i.e. fertilization rate, implantation rate, clinical pregnancy rate, on-going pregnancy rate and live birth rate. These results again confirm the findings of the only previous investigation. ${ }^{2,4}$

\section{Clinical relevance}

Treatment with uHMG or with combination could achieve the comparable clinical results with better oocyte and embryo quality. As addition of HMG in combination protocol and $\mathrm{u}$ HMG alone reduces the whole cost of stimulation, which is fruitful for poor infertile couples in developing countries like India where resources are limited.

\section{CONCLUSION}

This study found that the uses of HP hMG alone or in combination with rFSH are valuable, comparable and cheaper options for COS. But in future it may be difficult to have urinary $\mathrm{HMG}$ as it is manufactured from urine of menopausal women.

\section{ACKNOWLEDGEMENTS}

We thank Dr. Lakshmi Sanmugsundaram (senior consultant) for her support in the study

Funding: No funding sources

Conflict of interest: None declared

Ethical approval: The study was approved by the Institutional Ethics Committee

\section{REFERENCES}

1. A multicenter trial. European and Israeli Study Group, 2002.

2. Pacchiarotti A, Sbracia M, Frega A, Selman H, Rinaldi L, Pacchiarotti A. Urinary hMG (Meropur) versus recombinant FSH plus recombinant LH (Pergoveris) in IVF: a multicenter, prospective, randomized controlled trial. Fertil Steril. 2010;94(6):2467-9.

3. Tesarik J, Mendoza C. Effects of exogenous LH administration during ovarian stimulation of pituitary down-regulated youg oocyte donors on oocyte yield and developmental competence. Hum Reprod. 2002;17:3129-37.

4. Cochrane Database of Systematic Reviews 2011, Issue 2. Art. No. CD005354.

5. Murber A, Fancsovits P, Ledo N, Szakacs M, Rigo J, Urbancsek J. Impact of highly purified versus recombinant follicle stimulating hormone on oocyte quality and embryo development in intracytoplasmic 
sperm injection cycles. Acta Biol Hung. 2011;62(3):255-64.

6. Murber A. Impact of highly purified versus recombinant follicle stimulating hormone on oocyte quality and embryo development in intracytoplasmic sperm injection cycles. Acta Biologica Hungarica. 2011;62(3):255-64.

7. Gerli S, Bini V, Favilli A. Clinical efficacy and costeffectiveness of HP-human FSH (Fostimon®) versus rFSH (Gonal-F®) in IVF-ICSI cycles: a metaanalysis. 2013;29(6).

Cite this article as: Vishwakarma $\mathrm{P}$, Shankar K, Joy I, Varma TR. To compare the effectiveness of recombinant gonadotropin versus the combination of recombinant follicle stimulating hormone and highly purified human menopausal gonadotropin versus urinary human menopausal gonadotropin alone for ovarian stimulation in women undergoing in vitro fertilisation or intracytoplasmic sperm injection treatment cycles. Int J Reprod Contracept Obstet Gynecol 2016;5:1827-31. 